\title{
EI Desarrollo y las Políticas Culturales en América Latina
}

\section{EL ESCENARIO CULTURAL LATINOAMERIGANO}

\section{La identidad Latinoamericana.}

Es necesario definir lo que es la "identidad cultural latinoamericana". Gran parte de los ensayos filosóficos, históricos o sociológicos acerca de América Latinat como un todo cuestionan una concepción globalizante clel hemisferio $y$ llegan, incluso, en algunos casos, a negar la existencia de una América Latina como sujeto de una realidad propia $y^{\prime}$ de permanente vigencia. Sin embargo, más allá de las elaboradas diferenciaciones y definiciones que llevan a esta controversia, es un heoho que América Latina tiene una presencia histórica, económico-política y cultural en el mundo contemporáneo que tiende, progresivamente a afirmarse, y que esta realidad es la expresión de un "ser" latinoamericano.

Se podrá cuestionar el aserto argumentando la aparente incapacidad de nuestras naciones para mantener en forma sostenida y progresiv'a su marcha hacia niveles superiores de integración nacional de toda indole. Pruede subrayarse también que nuestros vínculos de "dependencia" de los centros hegemónicos en el concierto internacional tienden a afianzarse. $\mathrm{X}$ más aun, que la dicotomia entre lo hispánico y lo lusitano no sólo está aún lejos de ser superada, sino que especialmente, a juicio de muohas pesimistas, sus posibilidades de convergencia son más débiles hoy que ayer.

Estos juicios pertenecen al trasfondo de lo que pudiéramos denominar nuestra "Ieyenda negra", sombra permanente con que siempre se ha tratado de rodear a nuastro continente. En algunos casos esa leyenda ha emanado de paises política y económicamente más avanzados. En otros, sin embargo, han sido los propios intelectuales $y$ clirigentes latinoamericanos quienes, con cierto masoquismo, acentúan preferentemente nuestras intrínsecas debilidades. Esta última critica deformante es sin duda la más peligrosa. En los centros industrialmente más avanzados, con motivo de haberse creado una mayor sensibilidad frente a la emergencia del denominado Tercer

\footnotetext{
* Trabajo presentado en el Seminario sobre Nuevo Orden Económico Internacional y Valores Culturales, organizado por el Instituto Intercontinental de Cooperación, Madrid, en julio de 1970, y reproducido con autorización del autor.
} 
Munclo, el rol de América Latina tiende a ser más valorizado. Ha s:do mi experiencia personal, clesde la perspectiva del desarrollo económico, que en los últimos quince ar̃os la importancia de Américr Latina en su conjunto, $y$ también en la inclividualidad de sus naciones, tiende a tomar más fuerza.

Este reconocimiento de la mayor gravitación de nuestro contirente tiende a manifestarse también por parte cle otras regiones del Tercer Mundo. Lil circunstancia de haber intentado procesos de afirmación nacional descle hace más de 150 años, recorriendo caminos que otros pueblos sólo han comenzado a seguir en las últimas décadas, constituye un elemento que podríamos sumar a nuestro haber, en una coyuntura histórica clonde se está buscando "un nuevo orden internacional".

El "ser" latinoamericano tiene una connotación propia a través de su intrinseca fuerza hacia una integración cultural permanente, que se manifiesta desde el momento mismo en que los navegantes ibéricos desembarcaron en el Nuevo Continente. Desde el siglo xw en adelante se tha producido en términos masivos y constantes $-y$ por qué no decir generosos-, un proceso sostenido de fusión cle los valores culturales de distintos origenes écnicos, entre grupos humanos provenientes de estudios listóricos en muy diverso grado de evolución.

La verdadera definición de América Latina es haber siclo el activo crisol de la absorción cultural recíproca cle lo ibérico, lo indígena y lo africano durante los tres últimos siglos. Aunque aparentemente los españoles y portugueses pudieron haber determinado o definido en forma tangible la fisonomía cle esa fusión, de thecho la gravitac:ón autóctona tuvo una fuerza tan cleterminante que llegó a influir sobre el modelo europeo, proyectándose una forma cultural indiana sobre la peninsula. Esta realidad, prevaleciente entre los siglos $x v^{\prime}$ y xviri, se enriquece con los nuevos flujos inmigratorios europeos incorporados al Continente a lo largo del siglo XIX y en el presente siglo. Es interesante constatar que estas nuevas migraciones siguen, por regla general, la tendencia histórica de una asimilación fluida y no cliscriminada. Es decir, la aparición de minorías raciales que se constituyen en grupos diferenciados y aun en núcleos de poder -como ha sido el caso en los Estados 'Unidos-, no corresponde a la experiencia latinoamericana.

\section{Proyccción de lo lalinoamericano.}

En las últimas décadas el "ser" lątinoamericano tiende a proyectarse hacia otras extensiones geograficas. La separación de las regiones 
del Caribe inglés $y$ holandés de sus antiguas metrópolis ha agregado un interesante escenario geográfico y cultural a un mundo que hasta entonces era predominantemente iberoamericano. El "nuevo" Caribe t.ene profundas raíces históricas y étnicas comunes con los otros paises latinoamericanos. Esto ayuda a explicar el ponqué se ha protucido en un plazo relativamente corto un trabajo multinacional conjunto a través de un entendimiento en torno a objetivos comunes. ILa reciente creación de SELA (Sistema Económico Latinoamericano), iniciativa en cuya realización las nuevas naciones del Caribe tuvieron importante participación, es una experiencia tangible del proceso que estamos destacando.

Las migraciones de los países latinoamericanos y caribeanos hacia los Estados Unidos, por circunstancias históricas distintas y sujetas a realidades cambiantes, ha tenido un profundo impacto en ese país en los últimos años. Los quince millones de mexicanos, cubanos, portorriqueños, caribeanos en general, y más recientemente la migración de hombres y mujeres de paises al sur del Ecuador, than tendido a formar una poderosa minoria racial y lingǘstica en la América Sajona, cuyas proyecciones y trascendencia sólo ahora se están dejanclo sentir.

Agreguemos que descle la revolución cle los "claveles rojos", de abril de 19714, hasta la fecha presente, el proceso de democratización y apertura, tanto en Portugal como en España, está creando un diálogo histórico-cultural de esas naciones con América Latina de insospechadas proyecciones.

Hoy podemos hablar con más fundamento que nunca de la existencia de una dimensión ibérica" para connotar intereses y problemas comunes entre las madres patrias $y$ las naciones que cllas contribuyeron a dar nacimiento.

El término "latinoamericano" se emplea frecuentemente para definir una categoría cle desarrollo económico y socjal más atrasada que la anglosajona. ISin embargo, aun cuando esta diferenciación es válida, clescle un punto de vista semántico lo latinoamericano expresa de hecho una gran convergencia de pueblos que presentan una problemática común. El "ser" latinoamericano es básicamente un proceso histórico-cultural pasado, presente y futuro. La permanente aibsorción e integración de culturas que se realiza en esta parte del mundo proyecta una imagen con sus características propias. Es el escenario cultural, de gran potencialidlad y de mayor sino cosmopolita donde emerge la realidad esencial latinoamericana. De ahi que para nuestras naciones se plantee en forma cada vez más def:nida la necesidad de políticas culturales que puedan accionar esa realidacl. 
Por su grado de maduración histórica, América Latina ha experimentado, en el curso de los últimos 30 años, un profundo impacto de modernización. Es en este período, que se inicia con la segunda post-guerra, cuando se definen con mayor claridad la naturaleza y características del sulbdesarrollo, lo que lleva a acunar una problemática común que abarca a los países que no han alcanzado un grado de crecimiento económico y tecnológico avanzado bajo el concepto genérico de Tercer Mundo.

La preocupación generalizada de la comunidad internacional por superar esas condiciones de subdesarrollo ha hecho surgir teorías y politicas clestinadas a acelerar su ritmo de crecimiento económico. Una positiva proyección de ese "zeitgeist" está reflejada en la denom.nada Primera Década para el Desarrollo de las Naciones Uniclas, que comprende el periodo de 1960 a 1970 y cuya aspiración ha sido lograr un incremento del producto nacional bruto de los países en vías cle clesarrollo del orden del $5 \%$ anual. En la orientación de esas políticas se enfatiza el componente de carácter social para alcanzar un clesarrollo equilibrado.

Este énfasis desarrollista es en gran parte una nueva versión del concepto filosófico del "progreso", en bogn a partir del siglo xvir, $y$ transformado en vercladera filosofía y religión por parte de Ios paises occidentales en el siglo xwx.

América Latina puede, en la hora actual, mirar con satisfacción este mandato del progreso, en cuarto a las metas alcanzaclas por un desarrollo orientado hacia el crecimiento $y$ la acumulación material. En el curso de una generación se ha operado en el Continente un profunclo $y$ extendido proceso de cambio en las condiciones de la existencia cliaria. Tor otra parte, se presencia una duplicación de la población, lo que acarrea nuevas presiones sobre el sistema económico, político $y$ social. Esa mayor población cuenta con un alto porcentaje de menores de 20 años, lo que a su turno crea nuevas realidades sociológicas $y$ culturales. Paralelamente, se observa un extraordinario desarrollo urbano, en la mayoría de los casos, desgraciadamente, efectuado en términos desordenados e ineficientes. Sin embargo, desmintiendo a los agoreros de una catástrofe como producto de la explosión demogíáfica, las estadísticas señalan que pese al crecimiento poblacional, el promedio del nivel de vida tiende a elevarse. Una parte sustantiva de las alteraciones materiales anotadas responde a mejores condiciones de la productividad en el jistema económico, como consecuencia de un proceso sostenido de industrialización y de mejoras, y, en ciertos períodos, en las relaciones del intercambio exterior. A ello podemos agregar las más 
altas tasas de capitalización en lo interno y en lo externo, y el cam. bio de muchas de las viejas estmucturas en función de estas nuevas fuerzas económico-sociales.

Este cuadro que sumariamente estamos describiendo no puede sorprendernos si consideramos los recursos naturales $y$ humanos de América Latina, a la luz de una vocación de progreso, en el mejor sentido de la tradición occidental. Prorque aun cuanclo América Latina sea por esencia el resultado de un mestizaje permanente, su respuesta ante los desafíos del mundo politico-económico ha tenido siempre la connotación propia de la cultura occidental.

En el periodo colonial los modelos de las metrópolis definen la estructura de la organización social de nuestros países en sus diversos aspectos. Lograda la emancipación, se tratan de adoptar los esquemas que se consideraban más avanzados en las sociedades curopeas y en los Estados Unidos.

Decimos que "se tratan de acloptar" porque es bien conocida la dicotomía permanente que se produce en el siglo xix entre las aspiraciones cuiturales e intelectuales de una minoria selecta $y$ las fuerzas regresivas que se expresan en gran parte de estos pueblos en un caudillismo que determina una historia sangrienta y caótica. Ese caudillismo, sin embargo, aun cuando frustra las aspiraciones de los grupos intelectuales thacia un mayor nivel oultural, proyecta una concepción "progresista" en lo material. No otra cosa representan en la historia latinoamericana los procesos de modernización realizados por Porfirio Diaz en México y Vicente Gómez en Venezuela. La apertura indiscriminada thacia el capital extranjero no refleja sólo un acto de dependencia de los centros económicos más avanzados, sino también la creencia de que nuestro atraso y "barbarie" podia ser superado bajo el alero de las sociedades industriales de la época.

América Latina tiende asi a absorber las concepciones decimonónicas en todas sus proyecciones: en lo económico, en lo educativo, en lo castrense, en la creación artistica. Nuestros paises cuentan siempre con sectores proclives a las ideas politicas y culturales más avanza. das de las sociedades occidentales. En las primeras décadas del siglo $\mathrm{xx}$ esa característica se acentúa. Las transformaciones que siguen a la primera guerra mundial y las nuevas realidades socioculturales de las sociedades más avanzadas tienen entre nosotros un reflejo directo.

\section{EL CONFLICTO CULTURAL}

Parecicra que el proceso que hemos recordado tiende a mantenerse y repetirse en los últimos 30 años. Sin embargo, los clesarrollas de la 
áltima generación, por el proceso mismo de aceleración histórica a escala global, han creaclo un choque entre las realidades culturales decimonónicas que vivimos hasta ahora, y los nuevos desafíos de dina sociedad cuy prioriclad es el crecimiento económico y los niveles de consumo.

El conflicto entre esn: realidad histórico-cultural y las nuevas motivaciones y fuerzas que emergen de la clenominada "sociedad de consumo" es bien conociclo en todo el Tercer Mundo, y constituye una de las preocupaciones internacionales más serias. Conservar la "identiclad cultural" de los pueblos nuevos se ha transformado en un slogan tal vez muchas veces no bien elaboraclo y definiclo, pero que expresa el malestar y desajuste propio de una alienación cultural. Es interesante constatar que este decho ha golpcado mís la sensibilidad del hombre latinoamericano que otras situaciones que pudiéramos consiclerar deformantes dentro de nuestra coexistencia cliaria.

Tal como lo hemos señalado en el capitulo anterior el conflicto se agudiza con la revolución, de alcance universal, en los medios de comunicación. El empleo masivo de la radio y de la televisión ha producido un escenario cultural nuevo que, aunque con caracteríslicas clistintas entre los diversos países y regiones latinoamericanas, hat creado un proceso de cambio muy similar.

Un parlamentario brasileño reflejaba csta preocupación proponiendo una cruzada nacional indispensable "para la salvación de la cultura brasileña que ahora sufre amenazas por todos laclos", preguntánclose "qué país es éste que lla llegado a olvidarse de sus hérocs sustituyéndolos por ridiculos mitos importaclos como los cow-boys del oeste norteamericano, cuya lejenda todos sabemos que es fruto cle la imaginación cinematográlica. ¿Qué país es éste que no puede transmitir a las genernciones que licgan ejemplos de hombres simples de nucstro pueblo? Tenemos que salvar lo que resta de la culLura ibrasileñit. Si no lo hacemos, corremos el riesgo de amanecer siendo otra nación, en la cual el sentimiento brasileño será apenas una referencia histórica.

Esta es una preocupación genewalizada en lat América Latina contemporánea: tenemos a la alienación cultural. Sin embargo, por regla general, nos vemos $\sin$ otras alternativas a opciones frente a realidacles de carácter irreversible, como es el caso de la revolución cie los medios audio-visuales. La formación creciente de una opinión y una conciencia de que "algo hay que hacer para evitar la perdida de nuestra identidad" es el mejor sustratum para alimentar las perspectivas de políticas culturales que hasta ahora, o han sido inexistentes, o bien se than orientado en función de una realidad que terminó con la Segunda Gruerra Mundial. 
FORMLAS DE UNA ALIENAGIÓN OLLTUKAL

E1 proceso de "alienación" cultural latinoamericana es, sin embargo, más profundo que las tangibles crosiones cxperimentadas por el impacto de los sistemas de vida de los Estados Uniclos y de Europa Occidental. Tal como hemos scrialado, la influencia más determinante en este proceso se produce a través de la presentación de. creaciones foráneas en la televisión, en el cine, la música, sistemas de anuncios y propagandas, etc. (mass media).

Menos aparentes, pero de igual o mayor trascendencia son las siguientes realidacles:

1) Las técnicas que determinan la producción, circulación y consumo de bienes y servicios constituyen un reflejo cada día más acentuado de lo que acontece en las sociedades técnica e industrialmente más avanzadas. Mucho se ha cliscutido acerca de la necesidad de contar con técnicas intermedias, gestadas y desarrolladas en función de nuestras propias necesidades. Sin embargo, lat verdacl es que ese planteamiento - sin clucla de toda validez-, no tha pasado de ser una expresión de buenos deseos, ya que en el hecho la evolución económica $y$ tecnológica latinoamericana se realjza en base a la absorción creciente del "know-how" extemo. Esto implica que las perspectivas de un mejoramiento cuantitativo - cualitativo de nuestras actividades dependan estrechamente del exterior.

2. IEl hecho de que el sistema productivo $y$ consuntivo esté influido grandemente por una ciencia y tecnologia externa determina que lo que genéricamente pudiéramos definir como la "formación de recursos humanos", particularmente el sistema educativo en sus variadas formas, esté también influida fuertemente por mocllos externos. Si las posibilidacies hacia el "desarrollo modernizante", de acuerdo con el criterio prevaleciente, están cladas en los estilos económicos y técnicos de las sociedacles avanzadus, es consecuente tratar de adoptar aquellos factores que son prerrequisitos para csos estilos.

Las reformas eclucacionales están a la orden del clia en América Latina. Ellas se inspiran cada vez más en Ias respuestas que dan Ios paises industrinlizados a la interrogante de cómo adaptar en mejor forma el régimen educativo a la necesidacles del mercado del trabajo. Es en el campo de la educación universitaria donde este proceso de traslado institucional se hace más evidente. La adaptación se produce no sólo en las denominaclas ciencias naturales o exactas, sino también en las ciencias sociales y humanas; 
esto último contribuye a debilitar el conocimiento y vivencia de nucstros propios valores.

A lo anterior hay que agregar también la tendencia natural de los futuros expertos profesionales por lograr niveles más elevados en su formación mediante estudios en el extranjero, para lo cual las posibiliclades de becas y otras formas de asistencia son importantes factores, Las nuevas generaciones latinoamericanas consideran cada vez más que esta nueva "inmersión" formativa en sociedades tecnológicamente más avanzadas les proveerá de mayores antecedentes $y$ conocimientos frente a un mercado competitivo, por recursos humanos. No constituye, pues, la tendencia al estudio en el exterior por regla general una aspiración a un perfeccionamiento intrínseco, sino que fundamentalmente un medio de tener mejores herramientas para enfrentar el nuevo tipo de sociedad modernizante que está cmergiendo en América Latina. Estas circunstancias son las que ay'udan a entender mejor la "fuga de talentos": hay un alto porcentaje de jóvenes latinoamericanos para los cuales el contorno material y cultural de su propio país es sólo una "mala copia" cle la sociedad avanzada, particularmente, de los DE. UU. Si se les dan las circunstancias para realizar su vida en lo que para ellos es el ideal de sociedad; ¿por qué continuar en un camino que disminuye sus propias perspectivas individuales?

$3^{\circ}$ Lo que hemos anotado en relación a la economía y a la educaciỏn se expresa en forma generalizacla en otras manifestaciones cle lá vicla social: en la creación institucional y administrativa, en las cliversas formas que adopta la vida política en el régimen de vida familiar.

\section{FACTORES PARA UNA AFIRMAGIÓN CULTURAL LATINOAMERICANA}

\section{Integración Cultural.}

Al señalar en los párrafos anteriores estas nuevas facetas de la realidacl cultural latinoamericana, no lo hacemos en función de criterios críticos o de una escala de valores preestablecida, sino como el testimonio de situaciones que limitan la capacidad propia y autónoma de expresión. Tampoco pretendemos plantear la opción de un "latinoamericanismo" excluyente $y$ aislacionista. Ello sería ahistórico, en un continente cuya csencia misma está constituida por la absorción e integración de valores culturales de orígenes diversos, según lo hemos recordado en párrafos anteriores.

La proyección de un "estilo" occidental clurante más de cuatro siglos, tiene, sin embargo, una caracteristica que la diferencia de la 
situación actual. Anteriormente, las corrientes cuiturales se incorporan en forma orgánica y armónica a nuestra realidad. Existió una presencia intelectual latinoamericana que, fortalecida por esas corrientes, creó un pensamiento propio. Tal vez la mejor expresión de ese proceso, en el siglo xIx, fue Andrés ỉ'ello, y en la misma línea podemos colocar a los "grandes" del pensamiento latinoamericano de ese mismo siglo y de las primeras décadas del sikglo xx; los argentinos Eoheverría, Alberdi y Sarmiento, Ingenieros, UJgarte, Gálvez y Rojas; los chilenos Lastarria, Bilbao y Vicuña Mackenna; los caribeanos Martí, Hostos y Pedro IFenríquez Ureña. Los mexicanos Justo Sierra, Vasconcelos y Hifonso Reyes; José Cecilio del Valle en Centroamérica; Rodó en Uruguay; Montaliro en Ecuador; González Prada, Mariátegui y Haya de la Torre en el Perú.

Distinta es la situación prevaleciente en la última generación. Salvo excepciones destacadas, particularmente en el campo literar.s, y de las antes plásticas se tiende a perder la afirmación de lo que nos es propio. Surgen decenas, centenas y miles de especialistas que de hecho forman parte de una realidad cultural externa.

La razón de esta incapacidad de expresión de nuestro "ser" se debe tal vez a la globalización acclerada cle los grandes desafios de la época contemporánea, y a la incapacidad de América Latina de haber proyectado una personalicad propia frente a una "civilización planetaria".

En más de alguna oportunidad he sostenido que el proceso económico-político de integración latinoamericana estaba tamenazakio. por una ley de "prescripción histórica". Los síntomas de esa situación se observan claramente en la actual realidad continental.

Pareciera que en el plano cultural se tiende a producir un proceso análogo. Sin embargo, clada la naturaleza intrinseca del fenómeno cultural, estamos aún en concliciones de encontrar una identidad colectiva. El futuro de América lLatina, en sus relaciones de toda índole con las demás regionas del mundo, depende precisamente de esa posibilidad de autoafirmación. Es decir que en función de esa perspectiva está trazado el camino del Continente que lo podría llevar a la formación de modelos políticos, sociales y económicos que expresaran nuesrai realidad autónoma, permitiéndonos así salir de la faja de los pueblos marginales y dependientes para proyectar $y$, lo que es más importante, poder actuar de acuerdo con nuestra personalidad específica.

Se podrá argumentar que lo anterior sólo es posible en cuanto haya fuerzas económicas y políticas tangibles que den sustento a esa realidad. Es evidente que si América Latina pudiera terminar la "tarea inconclusa" de su unificación, sería centro de poder en términos convencionales. Pero aun con oibstáculos que superar en 
el contorno económico-politico, se puede y se debe afirmar una realiclad cultural propia. En las actuales circunstancias, la tarea no parece imposible. En los últimos 15 años América Latina ha aprendiclo a conocerse a sí misma, y las naciones que la integran tienen una mayor conciencia recíproca de su pasado y destino común. $\mathrm{Ha}$ existido una fuerza unificadora cuyo ritmo tha sido más acentuado que los pasos dados a través de la creación de mecanismos ad hoc para integrarnos. El mismo proceso de modernización, técnico, cient́f́lico, económico, eclucativo e institucional que se produce en todos los ámbitos de la región, tha favorecido el acercamiento de los actores de este nuevo desarrollo histórico. El balance de los resultados de acciones conjuntas de países, grupos, instituciones e individuos que han traspasado las fronteras no ha sido apreciado ni expresado en su verdaclera trascendencia.

Aun cuando en su evolución cultural reciente América Latina está pagando el precio de deformaciones y aberraciones, se ha abierto, por otra parte, un escenario cultural que podría llevar a una integración profunda de nuestros pueblos, en términos desconocidos en otros periodos históricos con menores posibilidades de comunicación. Es por eso que en el campo del accionar cultural, deben reorientarse las preocupaciones estrictamente nacionales hacia expresiones subregionales y regionales. Las políticas culturales de los paises latinoamericanos deberán contar con un importante ingrediente multinacional, si desean dar una respnesta efectiva a las tareas y desafios que se proponen.

Hray además otros factores y circunstancias que nos permiten ser optimistas acerca de las perspectivas de nuestras políticas culturales. Pasaremos a resumir esos elementos en los párrafos que siguen.

\section{Enfasis internacional en las politicas culturales}

En el curso de la presente década se tha gestado ana movilización de opiniones, a diversos niveles, acerca de la importancia de la actividad cultural en el proceso de convivencia colectiva. Este nuevo énfasis ha reperciticlo en la preocupación $y$ acción de los golbiernos, $y$, en general, de instituciones de diversa índole tanto en el plano internacional como nacional.

Si embargo, ha sido en el foro multinacional representado por la UNESCo, como organismo especializado en la materia, donde el pro. ceso toma una mayor significación. Lia trascendencia de las últimas Conferencias. Generales acerca del problema cle las politicas culturales y su incidencia en la vida de los pueblos, con la mejor expresión de este enfoque.

Los siguientes párrafos de un discurso del ex Director General de la vivesco, señor Maheu, pronunciado en la Conferencia de Venecia 
acerca de las políticas culturales para la ipresente década*, expresan nítidamente esta nueva perspectiva en estos términos:

"Otra fuente del proceso que ha llevado a la noción de la política cultural es el desarrollo, que ha cobraclo una importancia bien conocida en el mundo actual, tanto en lo que se refiere a las ideas como a la acción. Lá idea de desarrollo como política nacional empezó a afirmarse y a extenderse, principalmente en el sistema de las Naciones Unidas, en el decenio 1950-1960. Al principio, su alcance se limitaba a las realiclacles económicas y' se ap.icaba casi exclusivamente a la elucidación de los problemas de los países tecnológica y económicamente atrasádos, esto es, los países que según esta perspectiva se han venido llamando descle entonces subdesarrollados. Pero también en este caso se ha producido una evolución muy significativa en el decenio de 1960-1970, llamado Primer Decenıo para el Desarrollo. En efecto, la noción de desarrollo se ha ampliado, diversificado y prolundizado progresivamente hasta englobar, rebasados los aspectos puramente económicos del mejoramiento de lat condición thumana, los aspectos liamados sociales. Y esto no se clebe solamente al descubrimiento de que ciertos factores sociales tales como la salud, la educación, el empleo, condicionan de hecho el crecimiento económico, sino también que los comportamientos o los motivos que inducen o deberian inducir a las opciones primordiales de un planeamiento global del clesarrollo, obedecen a ellos. El hombre es el agente y la finaliclad del desarrollo. $Y$ este hombre no es abstracción unidimensional del homo economicus; es el ser concreto de la persona en la pluralidad indefinida de sus necesidades, de sus posibilidades y de sus aspiraciones".

"El centro de gravedad de la noción de desarrollo se ha desplazado, pues, de lo económico a lo social. Hemos llegado ya a un punto en que esta evolución desemboca en lo cultural. Hasta los economistas reconocen yai que o bien el desarrollo es total o no es tal desarrollo $y$ que no es una metáfora hablar del desarrollo cultural; este clesarrollo es parte integrante y dimensión propia clel desarrollo total.

Las concepciones anteriores inciden en las nuevas perspectivas de estrategia para el desarrollo internacional en el Segundo Decenio para el Desarrollo, en torno al concepto de "calidad de la vida". No basta, para la acción orgánica de la comunidad internacional o de los paises aisladamente considerados, un crecimiento de carácter

*Informe Final de la Conferencia Intergubernamental sobre los aspectos institucionales, administrativos $y^{\prime}$ financieros de las políticas culturales. Yenecia, Agosto/Septiembre, 1970. 
cuantitativo, sino que es inclispensable ajustar ese progreso a los requerimientos más concretos y específicos de lombres que están viviendo en un medio social de carácter cambiante.

Tengamos en cuenta también que la acentuación irreversible de los nacionalismos en el mundo actual, especialmente por parte de los países en vias de clesarrollo, no sólo se expresa en una aspiración de conquistar lo que genćricamente podriamos denominar su "independencia económica", sino también en el encuentro de un destino de carácter thistórico, en el que los valores culturales tienen una importancia fundamental. En algunos casos se trata de acentuar o replantear valores que, como consecuencia de un pasado colonial, pueden haberse perdido o diluido; en otros casos, se trata de crear una imagen cultural sobre la base de los elementos propios y distintivos de Ia existencia de todo pueblo. Estas aspiraciones, como es sabido, tienen muchas veces una climensión especial en función del reencuentro de las raices comunes cle carácter histórico y cultural de paises que a través de los años han. vivido desmembrados. Tal es el caso de los países latinonmericanos, de los pueblos árabes y de algunos grupos de paises africanos.

De darse las condiciones de clesarrollo institucional y técnico en sus paises miembros, los organismos internacionales de financiamiento podrán extencler su cooperación a promover el clesarrollo institucional en el campo de la cultura, a través de planes de asistencia técnica, o bien mediante préstamos para inversión destinados a consolidar, modernizar y expanclir los institutos nacionales de financiamiento del desarrollo cultural, a los cuales luego nos referiremos.

Seria también importante que los organismos internacionales de financiamiento tomaran la iniciativa de financiar estudios básicos que buscaran relacionar, en forma científica, el valor que se puede atribuir al elemento cultural para el desarrollo de una sociedad. En fecha reciente, los servicios de la unesco encatigados del desarrollo caltural han progresaclo mucho en esta materia con la creación y cl establecimiento de una metodología estadística que está tratando cle cuantificar los aspectos culturales a los que themos hecho referencia.

En el caso de que estos organismos multinacionales resolvieran entrar con mayor decisión en el campo del desarrollo cultural de sus países miembros, cleberían tener en cuenta, naturalmente, las prioridacles que establezcan los prop:os países dentro de sus planes cle desarrollo; al mismo tiempo deberian concitar en torno de los proyectos por financiar la conjunción de esfuerzos internos en el plano de los recursos tanto financieros como humanos, dando énfasis el fortalecimiento institucional que requiere In actividad beneficiada 
para que, en el largo plazo, ésta pueda disponer de la dosis necesaria de autosustentación.

\section{Reaccioncs frente a la Sociedad de Consitmo.}

Los procesos histólicos tienden a generar sus propias reacciones. Hemos recordado ya que en Anerica Latina ha ido imponiéndose un estilo de vida nuevo, como consecuencia del rápido crecimiento cconómico observable en la última generación.

No podemos extrañarnos que un "economicismo" y un "tecnicismo" al cual no habiamos estado acostumbrados, y que en gran partc ha siclo absorbido clescle fuera, cree también una insatisfacción en los inclividuos cle una sociedad 'que, creyéndose destinada originalmente a satisfacer sus propias aspiraciones, ve surgir en la práctica un factor ajeno de creación de nuevos problemas. El predominio incontrolable de ansias de fáciles ganancias, expresado en una especie de "darwinismo" en la lucha por li vida diaria no habia sido presenciado antes por el latinoamericano, y muchos thace reflexionar acerca de la validea del modelo que se nos ha impuesto. Llos efectos demostrativos del lujo, de la popularidad fácil y susceptible a comprarse en función de la pulblicidad, la erosión en los vínculos familiares, etc., nos hace meditar acerca de los méritos y ventajas de un clesarrollismo ciegamente aplicado.

Por otra parte el latinoamericano no encuentra la respuesta ideal en los niveles alcanzados por las sociedacles más avanzaclas. La información internacional proyecta dia a día los serios problemas de la ecología, de la criminalidad, de la lucha generacional y la insatisfacción extendicla entre el hombre medio de ese mundo qne nos habiamos impuesto como modelo digno de imitar. $Y$ lo que es más grave, ya no sólo nos cabe observar en el exterior esos subproductos del progreso, sino que estamos yn sufriendo sus efectos deformantes. Efectilvamente, en América Latina ya existe alarma por el proceso de destrucción y erosión del medio ambiente, creado por el desarrollo, y muchas de nuestras ciuclacles se than transformado en centros urbanos caóticos, inhóspitos e inseguros, doncle la vida del hombre ha dejado cle ser un agrado.

Nada thay de extraño que en contacto con esta nueva realidad el hombre latinoamericano añore las circunstancias de mayor equilibrio $y$ de menor presión social que conociera en períoclos anteriores, Es cierto que existe un alto porcentaje de nuestra población que por su juventud no ha conocido otro estilo del devenir colectivo; sin embargo, los problemas emocionales $y$ el desajuste de esas nuevas generaciones ayudan también a crear una seria interrogante a las formas de vida que hemos tritado de implantar en estas últimas clécadas. 
Se crea así un ambiente propicio para analizar y valorizar elementos genéricamente denominados "culturales" y que no significan otra cosa que el encuentro equilibrado del hombre con su propio ser, con sus semejantes, con el pasado $y$ con las perspectivas futuras de la sociedad que está destinado a vivir. Es por esta razón que en América Latina, tal como en otras partes del Tercer Mundo hay una especial receptividad al concepto del encuentro o re-encuentro de una identidad cultural. Este concepto, que no tha sido objeto de definiciones más detalladas, surge como una respuesta intuitiva para alcanzar un equilibrio subjetivo y colectivo que las sociedades de consumo parecieran negar. Son especialmente los pueblos del Tercer Mundo quienes conservan la memoria de épocas para ellos más armónicas $y$ auténticas donde la identidad cultural tiencle a thacerse idea fuerza.

\section{Tendencias hacia expresiones culthtrales autóctonas}

En el caso de América Latina, tal como en otras colectividades que han experimentado deformaciones de su "ser" cultural como consecuencia de las alteraciones en el contexto económico-tecnológico, se está manifestando una tendencia al encuentro de aquellos valores que se consideran autóctonos y que definen históricamente la personalidad de un pueblo. Esta tendencia puede revestir múltiples formas $y$ puede ser o espontánea o dirigida.

Entre esas modaliclades presenciamos una nueva wigencia en el estudio de la historia patria o de las biografías de individuos destacados, $y$ el interés intensificado por expresiones de la creación artística de periodos pasados, particularmente la danza, las canciones populares, las expresiones de la anquitectura, de la escultura y de la pintura. Oibservamos en muchos países un inspirado redescubrimiento de expresiones culturales que habian sido objeto de olvido por largos periodos o que, estando presentes, mo se les atribuía mayor valor.

En el mismo orden de ideas subrayamos la importancia que están tomando las expresiones folklóricas en muchos paises. América Latina se acostumibró, clurante la época de la influencia europea en nuestra cultura, a considerar las expresiones indígenas, de los sectores rurales o bien aquellas de sectores marginales, como productos empíricos y primitivos, sin mayor valor intrínseco, llegándose en algunos casos a ignorarlas o soterrarlas para no aparecer como manifestaciones de pueblos "poco civilizados".

A veces, estos procesos de revivencia de lo autóctono han sido de carácter espontáneo, frecuentemente por la vuelta a estilos más sencillos y auténticos como reacción a etapas imitativas de expresiones culturales foraineas más elaboradas. Sin embargo, ha surgido tam- 
bién una conciencia clara de la necesidad de afirmar una identidad cultural, estimulada por centros de estudios e investigación universitarios, que han logrado promover y orientar la capacidad creadora hacia el reencuentro de los ralores propios de la cultura nacional.

A manera de ejemplo, podríamos mencionar algunas experiencias tales como los grupos de danzas, que en muchas regiones de América Latina han efectuado una resurrección de bailes autóctonos, y' en otra línea, más inmediata frente a la realidad actual, la "música de protesta" que surge del seno de la canción popular latinoamericana.

\section{El Artisia Latinoamericano.}

Hemos enfocado más bien un contorno cultural latinoamericano de carácter genérico sin referirnos más especificamente a las formas individuales de la creación artistica. Importante es recordar sus caracteristicas, particularmente en la literatura, como asimismo en las artes plásticas, música y expresiones de la arquitectura en muchos países.

Si consideramos la función desempeñada por el "artista" latinoamericano, encontraremos en él una de las fuerzas más vigorosas para la afirmación cle nuestra iclentidad cultural. En toda América Latina la historia de la cultura testimonia la presencia de creadores que fueron influidos conjuntamente por su medio y por ideas fuerzas que venían del exterior. iLa personalidad del artista latinoamericano empieza a definirse en función de una mayor definición política de nuestras repúblicas a fines del siglo pasado aun cuando es difícil generalizar sobre este proceso, ya que el ritmo de evolución de nuestros pueblos ha sido tan diverso.

Las guerras de la independencia, los largos años de ananquía y la inestabilidad política frustraron las posibilidades de una mayor creación artistica. HEay historiadores de la cultura que sólo identifican una "personalidad artística latinoamericana" thacia el final del siglo xIx, con la aparición del denominado movimiento "modernista". Toma en tal sentido, especial relevancia, la figura de Rubén Dario.

Existe una connotación permanente en el artista latinoamericano: su preocupación tangible por el medio social que lo rodea. La ma. yoría de nuestros artistas tha tenido una clara conciencia de su misión social. Particularmente en las últimas décadas, en que los desniveles y contradicciones de nuestras comunidades se hacen más evidentes, $y$ en la medida en que se ha producido una mayor conciencia y mejor información sobre la situación de los sectores mayoritarios de nuestras poblaciones, la creación artística ha ido tomando más fuerza en sus definiciones y paralelamente adquiriendo una mayor influencia sobre el medio que le rodea.

Sin negar la importancia de todos los sectores de la creación artís- 
tica, el proceso anterior se refleja fundamentalmente en la literatura. Aun más, pudiéramos decir que su impacto alcanza no sólo a nuestras propias socieclades sino que tambien ha logrado proyectar una imagen de tAmérica Latina hacia el mundo en general. Allí está la difusión $y$ popularidad de nuestros grancles escritores y poetas contemporáneos, cuyas obras se han transformado en creaciones de trascendencia internacional.

Indudablemente que la lunción del artista tiene un significado esencial en la búsqqueda de una identidad cultural. El artista latinoamericano, que en el siglo xay y primeras décadas del siglo $\mathrm{xx}$ se nutre de la rica cvolución cultural occidental, comienza a mirar en la última generación a la propia realidad de nuestro continente y se incorpora a ella, participanclo y descubriéndole sus auténticas características. Lua tradición de Rodó sea tal vez la mejor expresión del inicio de este proceso.

Nuestras politicas culturales cleberán utilizar esta fuerza como un factor determinante para la preservación de la identidad que se quiere mantener en los pueblos. Sin embargo, obvriamente, ellas no podrán definirse en función del artista como ente aislado, sino considerando el conjunto de factores y elementos que determinan una realidad cultural. Su acción deberá estar orientada hacia el estímulo y promoción de individuos cuya creación aún no ha sido reconocida a niveles nacionales o mundiales, poniendo especial énfasis en evitar el elitismo, ya que su propósito no es favorecer exclusivamente a los sectores que en forma tradicional han sido los consumidores de los bienes de la cultura. Es decir que las políticas culturales deberán enfocar el amplio escenario de la realidad cultural de un pueblo, donde el creador individual desempeña sin duda una función trascendente.

\section{HAGI LA FORMULACIÓN DE NUEVAS POLÍTICAS CULTURALES}

En todas partes es invocado el acrecho a la cultura propia como uno de los derechos del hombre en la lucha contra las discriminaciones raciales, étnicas, lingitisticas y culturales. Sin perder su función polilica de liberación, la identidad cultural se extiende al dominalo social $y$ cconómico gracias a la brisqueda actual de un nuevo orden económico internacional. Se hace cada dia más evidente que el establecimiento de ese nuevo orden implica que cada pais tome plena conciencia de su identidad y vocación.

(Del plan a mediano plazo de la unesco, 1977-1982). 


\section{El nucvo enfoque.}

América Latina ha estado viviendo un acelerado proceso de crecimiento económico que, desgraciadamente, no pareciera dar la respuesta integral a las inquwetudes del hombre latinoamericano, ni consolidar una posición internacional de conjunto en. nuestro continente, que lo permitiera transformarse en uno de los grandes "polos" del pocler en ese escenario.

Naturalmente, no themos podido en las ppŕginas anteriores entrar a un análisis en profundidad de los grandes factores condicionantes de nuestra realidad cultural. Sin embargo, hemos mencionado la importancia que tha tenido para el continente en las últimas décadas la explosión demográfica, el acelerado y desordenado proceso de urbanización, la gravitación de los sectores mayoritarios de la población menores de 20 años, la contradicción entre el padrón importado de la sociedad cle consumo, y la herencia y vigencia de una escala de valores culturales heredada y absorbida sustantivamente de la tradición occidental.

Para el futuro latinoamericano es innegable que el escenario cultural debe constituir uno de los instrumentos decisiros, y, por qué no decirlo, el más decisivo de todos. Tal como venimos en señalarlo, no ha sido un acaso el reconocimiento cosmopolita de nuestros grancles escritores, a través de los galardones de Premios Nobel recibidos en las últimas décadas por Gabriela Mistral, Miguel Angel Asturias y Pablo Neruda. La sensibilidad latinoamericana se siente interpretada en esta hora por sus grandes creaclores artístico-literarios.

Nuestra lengua se ha transformado asi en ariete de un, proceso que simultáneamente es de afirmación y de liberación. Carlos Fuentes define bien esta situación cuando expresa: "Si los hispanoamericanos somos capaces de crear nuestro propio modelo del progreso, entonces nuestra lengua es el único vehículo de dar forma, de proponer metas, de establecer prioridades, de elaborar criticas para un estilo determinado: de decir todo lo que no pueda decirse de otra manera. Creo que se escriben $y$ se seguirán escribiendo novelas en Hispanoamérica para que, en el momento de ganar esa conciencia, contemos con las armas indispensables para beber el agua y comer los frutos de nuestra verdaclera idlentidad. Entonces esas obras, esos pasos perclidos, esas Rayuelas, esos Cien años de soledad, esas Casas Verdes, esas Señas de identidad, esos Jardines de senderos que se bifurcan, esos Laberintos de la soledad, esos Cantos Generales, aparecerán como "la mitologías sin nombre..., anuncio de nuestro porvenir $^{\prime *}$

* (La nileva novela hispanoamericana, pág. 9S). Editorial Joaquim Martiz, Méjico, 1972). 
Las políticas culturales en nuestro continente no pueden enfocarse como frías respuestas burociáticas a aparentes necesidades sectoriales de la sociedad o del hombre. Tienen ellas que ser parte integrante de una realidad continental y nacional. Es por esa circunstancia que el accionar oultural en América Latina debe proyectarse en diversos planos que van clescle la región en su conjunto hasta pequeñas o aislaclas comunidades.

En el campo regional hemos tenido importantes agentes para provocar una movilización en torno a los objetivos culturales. UNESCO ha dado importancia acentuada a los procesos de regionalización como podemos leer en su último plan de mediano plazo: "Las regiones culturales raramente coinciden con las fronteras políticas. Eso determina que haya aproximaciones, intercambios y relaciones cordiales entre países que comparten un patrimonio aultural, común, aun cuando difieren en ciertos aspectos económicos, sociales e ideológicos". Es interesante recordar que no sólo son grupos de países en vías cle desarrollo los que tienden a la regionalización cultural, sino que también países avanzados, cual es el caso de las naciones que integran las Comunidades Eturopeas, que, en fecha reciente, discuten nuevos instrumentos cle integración y promoción culturales.

En nuestro hemisferio, clebemos destacar la labor y preocupaciones de la Organización de Estados Americanos, particularmente desde la creación del Consejo Interamericano para la Ciencia, la Educación y la Kultura. También debemos subrayar la importancia que los países del iPacto Andino tienden a darle a la cooperación e integración culturales a través clel IConvenio Andrés Bello. En el cuadro de esas preocupaciones se ha planteado la necesidad de crear mercados comunes para el libro, para la televisión, para el intercambio educacional, etc. En la práctica, desgraciadamente, a pesar cle las cleclaraciones y de convenciones oficiales bilaterales o multilaterales, los niveles electivos del trabajo cultural conjunto son aún débiles. Es interesante constatar que tal vez más importante que la convergencia oficial tha sido la convivencia y el intercambio indiviclual o institucional de experiencias en diversos sectores de nuestra creación cultural.

Somos de los convencidos que el Bistema Económico Latinoamericano (SELA) podría efectuar una importante colaboración en este campo a través de su política prioritaria de crear empresas multinacionales latinoamericanas. Hay actividades culturales donde lit multinacionalidad podría tener un firme apoyo a través de empresas de esa naturaleza, vgr. la industria editorial, cinematográfica, audiovisual, etc.

iEn el campo de la acción multinacional debemos subrayar la justificada preocupación por una preservación convergente de patrimonios thistóricos de orígenes comunes. La unidad de América Latina se 
expresa en realidades tangibles de creaciones culturales que sobrepasan nuestras fronteras y que tienen raices comunes, sean de origen precolombino, ibérico o mestizo. Recordemos sólo la realidad transnacional del patrimonio histórico maya, del andino, de las expresiones culturales comunes dejadas por las misiones jesuitas en algunos países del cono sur, de la expresión física del escenario histórico del Caribe clurante los siglos xvi al xvin, etc. Felizmente entidades internacionales y regionales en años recientes han estado preocupadas de estas realidades para el logro de una acción común de diversos gobiernos. Muchas veces lo anterior se ha efectuado como una proyección del pragmatismo del denominado "turismo cultural".

En relación a esta materia debemos anotar que a veces se observa una falta de coinc:dencia de puntos de vista acerca de la importancia que para un auténtico desarrollo cultural tiene el crecimiento turístico. Hay experiencias que parecen indicar que en muchos casos este último puede erosionar las condiciones de la oultura local, desde diversos ángulos, Sin embargo, creemos que es peligroso generalizar; las relaciones entre "turismo" $y$ "cultura" se deben someter a evaluaciones, sobre la base de las experiencias concretas de los últimos años.

La defensa y preservación del patrimonio cultural de la humanidad ha siclo una de las proyecciones mús interesantes de la cooperación internacional. La vNESCO, particularmente, ha jugado un papel sustantivo en esta acción. IEn algunos casos, se trata de una politica concertada para defender y preservar monumentos y creaciones humanas de un valor que trasciende las fronteras nacionales; en otros, se that tratado de cooperar con iniciativas nacionales que persiguen afirmar la imagen del pais sobre la base de su propia tradición cultural, como el descubrimiento o la preservación de sus tesoros artisticos to arqueológicos. Natunalmente, las preocupaciones anotadas inciden también en el citado campo del turismo cultural, $y$, en tal sentido, se vinculan al presente con la acción del financiamiento internacional.

\section{Recomendaciones y reflexiones finales.}

Nos atrevemos a suibrayar los siguientes aspectos que deben ser objeto de preocupación prioritaria para las políticas culturales de nuestros paises:

19 La necesidad de incorporar las politicas culturales en el contexto de los planes globales de desarrollo nacional. Obviamente la valorización de la acción cultural debe considerar fundamentalmente la acción individual $y^{\prime}$ de los grupos de diversa naturaleza que sean 
sus agentes. En función cle esa realidad debe risualizarse una acción promotora y coadyuvante del sector público en sus diversas manifestaciones, sea al nivel de los gobiernos centrales o federales, de los estados o provincias, de los municipios, etc.;

20. Las politicas culturales en América Latina necesitan una mejor institucionalización administrativa y legal, para lo cual la comparación de experiencia a nivel regional es de gran importancia;

3 o Tal vez uno de los aspectos más pospuestos es la existencia y efectividad de instrumentos financieros, públicos o privados, que tengan una capacidad promotora para la producción cultural. Tal como lo hemos planteado a lo largo de nuestro libro no hay fórmulas rígidas para estos fines: la respuesta puede eștar en estimulos fiscales $y$ crediticios de diversa naturaleza. Recordemos también la importancia que le hemos asignado a organismos especializados para el financiamiento del desarrollo cultural. No es una coincidencia que Argentina, hace ya más de 10 años, creó el Fondo Nacional de las Artes, anticipándose a una tendencia en boga actualmente en otros paises. Recordemos también que fue de otro pais del hemisferio, Jamaica, de donde surgiera el mensaje para la creación de un sistema internacional de cooperación financierocultural que, a partir de 1976, está representado por el Fondo Internacional de Promoción de la Cultura establecido por unEsco; '1. Finalmente, cleseamos subrayar la importancia de la creación de Centros de Formación de Recursos Humanos vinculados a las politicas cuiturales (administradores, planificadores, animadores, ctc.) y de unidades encargadas de la investigación en este vasto y complejo campo. Creemos que la rica experiencia universitaria latinoamericana puede servir de punto de apoyo para iniciativas de esta naturaleza, que en todo caso deben tener características multidisciplinarias.

En el permanente e irreversible camino de la convergencia latinoamericana, estamos seguros que en los próximos años los conceptos de integración e identidad culturales tendrán cada wez más vigencia, y serán cada vez más objeto de las preocupaciones regionales, subregionales y nacionales. Integración e identidad de la cultura en América Latina son términos que se nutren recíprocamente, a la luz de una interesante $y^{\prime}$ única experiencia que se inicia en el siglo $\mathrm{xvr}, \mathrm{y}$ que al final del siglo $\mathrm{xx}$ toma una nueva característica, a saber, su inserción con las realidades histórico-culturales de otros pueblos y continentes, de las que thasta ahora poco conocimiento teníamos.

América Latina está ya presenciando "un diálogo de culturas" para el cual. se enouentra particularmente preparada por su singular proceso de mestizaje. EI nuevo orden internacional, que supera una 
concepción meramente "economicista" de la civilización planetaria. por esencia, implica acentuar la convivencia entre partes diversas. El gran clesafio de la thumaniclad es de cómo permitir que la profundización de los valores nacionales, tendencia aparentemente centrífuga, pueda incorporarse armónicamente en un mundo que física y técnicamente se hace cada vez más estrecho.

Felizmente son muchos los líderes de la comunidad internacional qtue no sólo han reconocido la necesidacl de lograr esa síntesis dialéotica, sino 'que también están en sus respectivos planos actuando por lograrlo. El actual Director Gencral de la unEsco, A. M'Bow, señala al respecto: "Ni el crecimiento económico, ni el crecimiento científico y tecnológico pueden ser logrados a costa del sacrificio de la identidad cultural: una futura civilización mundial no tendria sentido si se basara en la uniformidad y en la banalidad, y no en el desenrolvimiento de las múltiples originalidades culturales. P'or tener sus raices en la tradición, la cultura es a veces considerada como un obstáculo a la modernización. Pero el hecho de los países que se niegan a posponer su identidad para aceptar modelos extranjeros, lejos de ser un thecho negativo, debe ser considerado positivo tanto del punto de vista nacional como global"*.

"Metas para el Futuro", Correo de usesco, Mayo 1977. 